\title{
Pembuatan Web Desa Karanggeneng Sebagai Sarana Informasi Desa Dan Promosi Desa
}

\author{
Andi Rahmad Rahim ${ }^{1}$, Syufa'atus $S^{2}$, Triska PL ${ }^{3}$., Rachmad Agus $\mathbf{P}^{4}$ \\ ${ }^{1}$ Dosen Program Studi Akuakultur, Universitas Muhammadiyah Gresik. \\ 2,3,4 Mahasiswa Program Studi Teknik Informatika, Universitas Muhammadiyah Gresik. \\ Email: Sayarusa@gmail.com, Triskaplestari@gmail.com, agungprasetyo552@gmail.com
}

\begin{abstract}
ABSTRAK
Website atau yang biasanya disingkat web adalah halaman informasi yang disediakan melalui jalur internet sehingga bisa diakses di seluruh dunia selama terkoneksi dengan jaringan internet. Website merupakan kumpulan halaman yang menampilkan informasi data teks, data gambar diam atau, data animasi, suara, video dan atau gabungan dari semuanya, baik yang bersifat statis maupun dinamis yang membentuk satu rangkaian bangunan yang saling terkait dimana masing-masing dihubungkan dengan jaringanjaringan halaman. Saat ini web merupakan salah satu media yang efektif untuk digunakan sebagai media informasi karena cakupannya yang sangat luas yaitu seluruh dunia. Dalam pembuatan web desa Karanggeneng kami membutuhkan waktu beberapa minggu, untuk template web kami menggunakan sistem informasi desa dari OpenSid kemudian setelah web desa siap, kami melakukan sosialisasi kepada perangkat desa Karanggeneng terkait penggunaan dan pemeliharaan web desa Karanggeneng. Dengan adanya web desa Karanggeneng ini diharapkan akan dapat menjadi sebuah media informasi yang baru dan bermanfaat baik untuk desa dan masyarakat desa itu sendiri maupun masyarakat luar.
\end{abstract}

Keywords : web, Karanggeneng, media, informasi, desa. 


\section{DedikasiMU (Journal of Community Service)}

Volume 1, Nomor 1, Desember 2019

\section{PENDAHULUAN}

Saat ini ada banyak kegiatan yang telah dilakukan di Desa Karanggeneng, seperti di bidang pembangunan infrastruktur, kesenian, pendidikan, pertanian dll. Citra dan Profesionalisme bisa dilihat dari kinerja yang sedang dan sudah dilakukan. Begitu juga di tingkatan desa, namun apabila prestasi yang sudah diraih, atau kinerja yang sudah dilakukan tidak di publikasikan, maka masyarakat tidak akan ada yang tahu apa saja prestasi yang sudah diraih maupun kegiatan yang dilakukan oleh desa Karanggeneng. Dengan memiliki website desa, perangkat desa bisa mempublikasikan kinerja yang sudah dilakukan, kegiatan yang sedang dilakukan, program kerja desa dan aneka informasi lainnya yang sekiranya positif untuk desa. Sehingga dengan adanya website citra dan profesionalisme desa menjadi terangkat.

Menanggapi hal tersebut, kami mahasiswa program studi Teknik Informatika berinisiatif untuk membuat sebuah website yang akan digunakan oleh desa sebagai media informasi dan promosi oleh desa Karanggeneng.

\section{A. Kajian Persoalan}

Saat ini desa Karanggeneng Kurang Populer di telinga masyarakat luar, oleh karena itu desa Karanggeneng membutuhkan sebuah media publikasi kepada masyarakat luar. Untuk mengatasi hal tersebut, maka kami berinisiatif untuk membuat sebuah website untuk desa Karanggeneng. Sehingga masyarakat luar dapat mengetahui segala sesuatu mengenai desa Karanggeneng, Misalnya kegiatan di bidang pembangunan, pendidikan, ekonomi, dll. Karena saat ini media yang paling efektif untuk melakukan promosi yaitu promosi secara online melalui internet. Oleh karena itu, kami memilih untuk membuat web desa karena dengan memiliki web desa akan membantu membuat desa Karanggeneng semakin dikenal oleh masyarakat luar. Selain itu dengan dimilikinya sebuah web desa akan menambah nilai lebih kepada desa di mata masyarakat luar karena akan terkesan lebih modern karena sudah menerapkan penggunaan teknologi informasi di desa. 


\section{METODE PELAKSANAAN}

Kerangka Penyelesaian Masalah

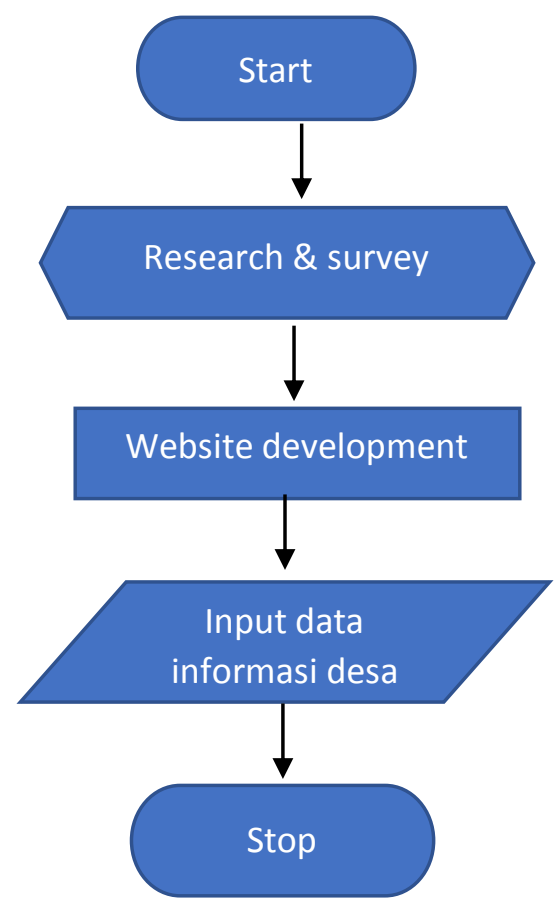

Gambar 1 Flowchart Penyelesaian Masalah

\section{A. Tujuan}

Diharapkan dengan adanya program pembuatan web desa, segala informasi yang ada pada Desa Karanggeneng dapat diketahui oleh masyarakat luas.

\section{B. Manfaat}

Segala informasi yang ada pada Desa Karanggeneng dapat diketahui oleh masyarakat luas, seperti informasi tentang kesenian dan kebudayan yang ada di desa Karanggeneng.

\section{Sasaran}

Seluruh perangkat Desa Karanggeneng.

\section{Peserta}

Seluruh perangkat Desa Karanggeneng.

\section{E. Acara Kegiatan}

Penyerahan website desa di balai Desa Karanggeneng. 


\section{DedikasiMU (Journal of Community Service)}

Volume 1, Nomor 1, Desember 2019

\section{F. Evaluasi Hasil}

Seluruh perangkat desa memberikan respon yang sangat baik saat kegiatan, bahkan setelah acara sosialisasi selesai, kami masih diminta untuk membimbing mereka untuk mengembangkan web desa Karanggeneng, dan juga mereka sangat berantusias dalam meneruskan dan mengembangkan web Desa Karanggeneng yang telah kami berikan.

Pembuatan web Desa Karanggeneng ini bertujuan untuk memberikan informasi kepada masyarakat luas tentang kegiatan apa saja yang telah dilakukan di Desa Karanggeneng, kesenian dan kebudayaan, kekayaan alam, dan juga tempat wisata yang ada pada Desa Karanggeneng. Sasaran dalam pembuatan web Desa Karanggeneng ini yaitu jajaran perangkat Desa Karanggeneng.

Program kerja "Pembuatan website Desa Karanggeneng" dilaksanakan dalam beberapa tahap dikarenakan dalam pembuatan web membutuhkan waktu yang cukup lama dan juga harus dengan ketelitian yang lebih karena sangat rumit dalam pembuatannya. Dalam melakukan program kerja ini dibagi dalam beberapa tahap. Tahap pertama yaitu melakukan survei di Balai desa Karanggeneng dan juga pengurusan izin kepada perangkat Desa Karanggeneng terkait pembuatan website tersebut, tahap kedua development website, tahap ketiga pembelian nama domain dan penyewaan hosting, tahap keempat pengisian konten, tahap kelima penyerahan website desa Karanggeneng.

\section{Tahapan pembuatan Web Desa Karanggeneng :}

\section{- Tahap pertama}

Survey dan research kebutuhan website desa yang terkait dengan program kerja prodi Teknik Informatika yaitu pembuatan web yang dilaksanakan pada tangga 15 Agustus 2019 di Balai Desa Karanggeneng. Kegiatan pada tahap ini yaitu konsultasi dengan beberapa perangkat desa terkait website yang akan dibuat mengenai konten apa saja yang akan di masukkan pada website desa dan juga pengumpulan informasi yang ada pada desa tersebut. Salah satu hal yang penting dalam tahap ini yaitu meminta izin kepada perangkat Desa Karanggeneng perihal program kerja yang akan kami laksanakan.

\section{- Tahap kedua}

Development website desa Karanggeneng, dimulai dari pemilihan tema website Karanggeneng, penyesuaian tampilan website desa Karanggeneng dengan konten yang 


\section{DedikasiMU (Journal of Community Service)}

Volume 1, Nomor 1, Desember 2019

akan dimasukkan. Pemilihan tema merupakan salah satu aspek yang penting, karena dengan pemilihan tema yang menarik maka minat pembaca website tersebut juga akan semakin bertambah, maka dalam hal ini pemilihan tema merupakan suatu hal yang dapat meningkatkan daya tarik dari pembaca. Tampilan pada sebuah website juga harus disesuaikan agar dapat selaras dengan tema yang telah dipilih. Pada tahapan ini dilaksanakan mulai tanggal 16 Agustus 2019.

\section{- Tahap ketiga}

Pembuatan akun akun yang akan digunakan pada pembuatan website. Pada tahap ini kami menggunakan Domainesia sebagai hostinger, oleh karena itu pada tahap ini kami melakukan pembuatan akun Domainesia. Selanjutnya kami memilih domain www.desakaranggeneng.com untuk digunakan sebagai domain web desakaranggeneng. Setelah itu kami melakukan pembayaran tagihan untuk pembelian domain serta biaya hosting untuk periode satu tahun. Tahap ini kami lakukan pada 25 Agustus 2019.

\section{- Tahap keempat}

Pemberian konten pada website desa Karanggeneng meliputi menu-menu yang ada pada website, diantaranya yaitu menu visi misi Desa Karanggeneng, Monografi Desa Karanggeneng, dimana informasi tersebut telah kami dapatkan pada tahap pertama sesuai dengan penjabaran perangkat Desa Karanggeneng saat rapat berlangsung. Konten yang lainnya beserta konten berita yang terdapat pada Desa Karanggeneng.

\section{- Tahap kelima}

Penyerahan website desa Karanggeneng ke perangkat desa Karanggeneng, serta memberikan sosialisasi cara pengelolaan website desa, kegiatan ini dilakukan pada tanggal 29 Agustus 2019 di balai Desa Karanggeneng kepada seluruh perangkat Desa Karanggeneng, pada kegiatan ini difokuskan untuk meningkatkan pengetahuan dan pemberian amanah untuk tetap merawat website desa Karanggeneng yang telah kami berikan kepada perangkat desa yang bersangkutan. 


\section{DedikasiMU (Journal of Community Service)}

Volume 1, Nomor 1, Desember 2019

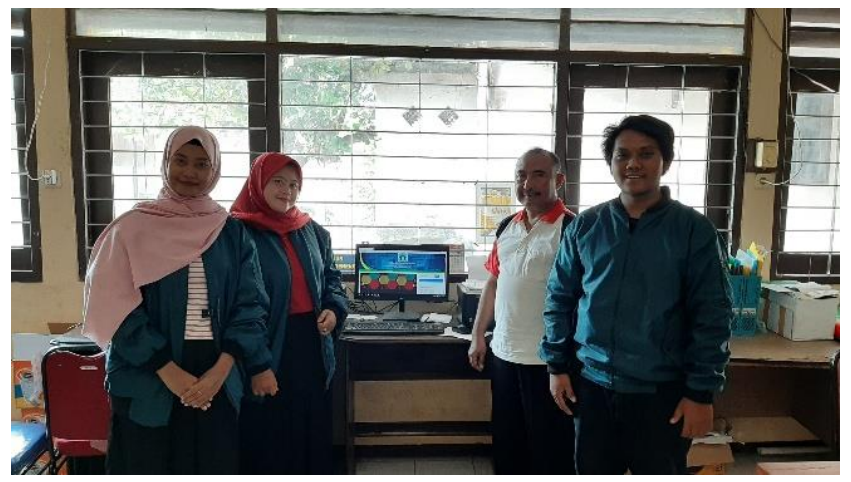

Gambar 2 Penyerahan Web Desa

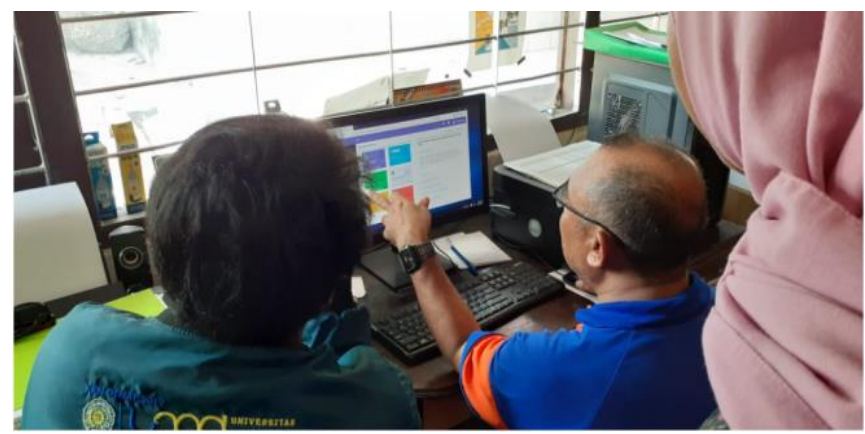

Gambar 3 Sosialisasi Web Desa

\section{G. Waktu dan Tempat Pelaksanaan}

Program kerja ini merupakan program yang pertama kali dilakukan di Desa karena sebelumnya belum ada pembuatan website desa untuk Desa Karanggeneng.

a. Wawancara kepada perangkat Desa Karanggeneng

Hari : : Senin

Tanggal : 5 Agustus 2019

Waktu $\quad: 09.00-11.00 \mathrm{WIB}$

Tempat : Balai Desa

Karanggeneng

b. Perancangan dan pembuatan website Desa Karanggeneng

Hari : Kamis - Minggu

Tanggal : 15 Agustus - 25 Agustus 2019

Waktu $\quad: 19.00-22.00$ WIB

Tempat : Posko dan balai desa

Karanggeneng 


\section{DedikasiMU (Journal of Community Service)}

Volume 1, Nomor 1, Desember 2019

c. Pelatihan mengisi website dan pemeliharaan website kepada perangkat Desa Karanggeneng

Hari : Kamis

Tanggal : 29 Agustus 2019

Waktu $\quad: 09.00-11.00$ WIB

Tempat : Balai Desa karanggeneng

d. Penyerahan website Desa karanggeneng kepada perangkat desa

Hari : Jumat

Tanggal : : 30 Agustus 2019

Waktu $\quad: 09.00-11.00 \mathrm{WIB}$

Tempat : Balai Desa karanggeneng

\section{HASIL DAN PEMBAHASAN}

Hasil program kerja yang dilaksanakan oleh progam studi Teknik Informatika dengan melaksanakan penyerahan web Desa Karanggeneng.

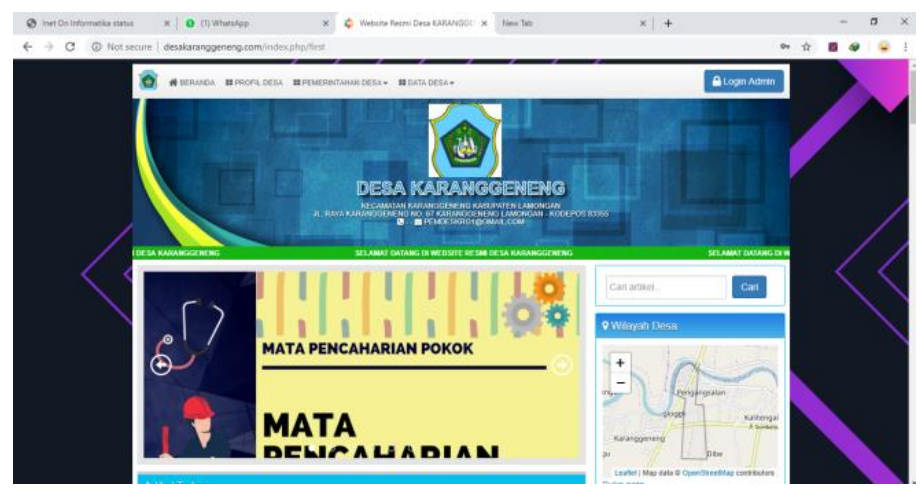

Gambar 4 Halaman utama Desa Karanggeneng

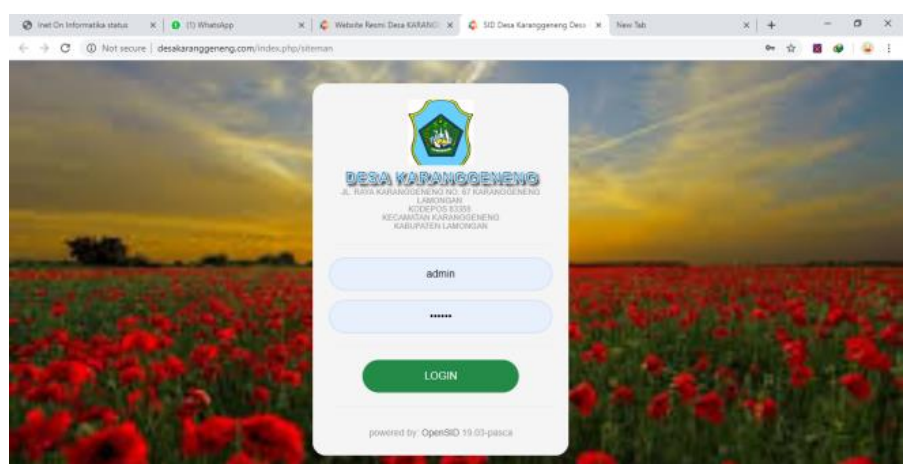

Gambar 5 Halaman Administrator Desa Karanggeneng. 


\section{DedikasiMU (Journal of Community Service)}

Volume 1, Nomor 1, Desember 2019

Sebelum mengerjakan pembuatan web desa, hal pertama yang harus dilakukan adalah survey dan research bersama perangkat Desa Karanggeneng tentang informasiinformasi yang terdapat pada desa Karanggeneng agar dapat dimasukan kedalam website yang akan dibuat.

Berdasarkan data dan informasi yang telah didapat tim prodi Teknik Informatika menghasilkan bahwa informasi desa Karanggeneng sangat minim di dapatkan oleh masyarakat luas, oleh karena itu desa Karanggeneng membutuhkan sebuah media informasi yang baru yaitu sebuah web desa. Karena web memiliki jangkauan yang sangat luas dapat diakses oleh siapapun yang ingin mengetahui hal-hal mengenai desa Karanggeneng.

\section{KESIMPULAN DAN SARAN}

Terbentuklah website Desa Karanggeneng sebagai sarana Informasi desa yang baru kepada masyarakat desa Karanggeneng dan kepada masyarakat luar yang ingin mendapatkan informasi tentang desa Karanggeneng.

Untuk kedepannya, diharapkan dengan adanya Website Desa Karanggeneng ini kedepannya mampu memberikan dampak positif yang berkelanjutan bagi warga dan perangkat Desa Karanggeneng. Begitu pula dengan perangkat desa diharapkan agar tetap menjaga, dan memelihara website yang telah dibuat oleh peserta program studi Teknik Informatika.

\section{DAFTAR PUSTAKA}

Cara Gampang.2018.https://www.caragampang.com/2018/06/fungsi-dan-manfaatmemiliki-website-desa/ (diakses pada: Agustud 2019).

Pro Web.2019.https://www.proweb.co.id/articles/web_design/website_adalah.html (diakses pada: Agustus 2019). 